\title{
Hubungan Anemia Dengan Prestasi Belajar Siswi di SMP Negeri Kelila Kabupaten Mamberamo Tengah Tahun 2018
}

\author{
Jenny Anna Siauta,Triana Indrayani, Kartini Bombing \\ Universitas Nasional, Jakarta \\ Corresponding author: Jenny Anna Siauta (jennysiauta2017@gmail.com) \\ Received: December, 16 2019; Accepted: January, 19 2020; Published: March, 162020
}

\begin{abstract}
ABSTRAK
Prevalensi anemia dunia berkisar 40-88\% pada remaja putri pada tahun 2013. Anemia pada remaja menyebabkan penurunan tingkat kebugaran, daya imun, daya ingat, dan daya konsentrasi. Daya konsentrasi yang rendah menyebabkan kemampuan belajar menurun dan akan mempengaruhi prestasi belajar remaja.

Desain penelitian ini bersifat deskriptif korelatif dengan pendekatan cross sectional. Sampel pada penelitian ini berjumlah 52 siswi. Teknik pengambilan sampel menggunakan Purposive Random Sampling. Instrumen penelitian terdiri dari Hb Quick Check dan nilai raport siswi. Data dianalisis menggunakan chi square untuk mengetahui hubungan antara anemia dengan prestasi belajar.

Hasil penelitian menunjukan bahwa ada hubungan yang signifikan antara anemia dengan prestasi belajar $(\mathrm{p}=0,000)$ maka $\mathrm{p}<0,05$.

Terdapat Hubungan yang signifikan antara anemia dengan prestasi belajar pada siswi di SMP Negeri Kelila Kabupaten Mamberamo Tengah tahun 2018.
\end{abstract}

Kata Kunci: Kinerja Kader, Partisipasi ibu, Penimbangan Balita, Posyandu

This is an open-acces article distributed under the terms of the Creative Commons Attribution-ShareAlike 4.0 International License.

\section{PENDAHULUAN}

Anemia merupakan salah satu masalah kesehatan di seluruh dunia terutama negara berkembang yang diperkirakan 30\% penduduk dunia menderita anemia. Anemia banyak terjadi pada masyarakat terutama pada remaja dan ibu hamil. Prevalensi anemia dunia berkisar 40-88\% pada remaja putri sampai saat ini masih cukup tinggi (WHO, 2013).

Anemia adalah kondisi berkurangnya sel darah merah (eritrosit) dalam sirkulasi darah atau massa hemoglobin, sehingga tidak mampu memenuhi fungsinya sebagai pembawa oksigen ke seluruh jaringan (Tarwoto, 2010).

Anemia banyak terjadi pada masyarakat terutama pada remaja dan ibu hamil. Prevalensi anemia dunia berkisar $40-88 \%$ pada remaja putri sampai saat ini masih cukup tinggi (WHO, 2013).

Berdasarkan data WHO (2014), prevalensi anemia di Asia Tenggara masih tinggi, seperti Brunei 20,4\%, Malaysia 30,1\%, Vietnam 24,3\% dan Thailand 17,8\%. 
Secara global jumlah penduduk usia remaja (10-19) tahun di Indonesia sebesar $26,2 \%$ yang terdiri dari 50,9\% laki-laki dan $49,1 \%$ perempuan. Dari data Riskesdas didapatkan prevalensi anemia gizi besi secara nasional pada remaja usia 13-18 tahun sebesar 22,7\% (Kemenkes RI, 2015).

Survei anemia oleh Dinas Kesehatan Provinsi Papua prevalensi anemia pada remaja putri usia 10-14 tahun sebesar 57,1\% dan pada wanita usia subur sebesar $39,5 \%$. Serta didapatkan data di kabupaten Mamberamo Tengah sebesar $12 \%$ yang meningkat dari tahun sebelumnya (Dinkes Prov Papua, 2015).

Anemia pada remaja disebabkan oleh beberapa faktor diantaranya menstruasi setiap bulan, kurangnya kadar zat besi dalam tubuh, kekurangan asam folat, vitamin B12, penyakit kronis, penyakit malaria, infeksi cacing tambang, keturunan atau genetic (WHO, 2014).

Anemia yang sering ditemukan adalah karena kekurangan atau defisiensi zat besi. Salah satunya disebabkan oleh mentruasi setiap bulan. Menstruasi menyebabkan remaja putri kehilangan darah $\pm 30 \mathrm{ml} /$ hari dan kehilangan zat besi $\pm 1,3 \mathrm{mg}$ per hari (Ahmadi, 2016).

Zat besi dibutuhkan tubuh karena berperan dalam perkembangan otak, sistem kekebalan tubuh, mielogenesis dan pemeliharaan mielin, berfungsi sebagai hantar rangsangan melalui sel saraf. Kekurangan zat besi dapat menurunkan aktifitas monoamine oxidase. Aktifitas neurologikal berfungsi dalam sintesa dopamin dan serotonin. Dopamin dengan tirosin berfungsi dalam koordinasi motorik. Serotonin berguna untuk neurotransmiter dan pemusatan perhatian atau konsentrasi. Kadar zat besi yang rendah berdampak pada kinerja kognitif dan berpengaruh terhadap konsentrasi belajar (Ahmadi et al, 2016).

Anemia dapat menyebabkan mudah merasa lelah, konsentrasi belajar menurun sehingga prestasi belajar rendah dan dapat menurunkan produktivitas kerja. Disamping itu juga menurunkan daya tahan tubuh sehingga mudah terkena infeksi (Mansjoer, 2013). Berdasarkan uraian diatas maka peneliti tertarik untuk melakukan penelitian tentang hubungan antara anemia dengan prestasi belajar siswi di SMP Negeri Kelila Kabupaten Mamberamo Tengah

\section{METODE}

Desain penelitian ini adalah penelitian deskriptif korelatif dengan pendekatan cross sectional. Cross Sectional desain yaitu suatu penelitian untuk mempelajari dinamika korelasi antara faktor-faktor resiko dengan efek, dengan cara pendekatan, observasi atau pengumpulan data sekaligus pada suatu saat (Point Time Approach) Penelitian ini dilakukan di SMP Negeri Kelila Kabupaten Mamberamo Tengah bulan Desember 2018 - Maret 2019. Populasi dalam penelitian ini adalah seluruh siswi kelas VII, VIII dan IX di SMP Negeri Kelila sebanyak 75 orang. Sampel yang dipakai dalam penelitian ini sebanyak 52 responden.

\section{HASIL PENELITIAN}

Tabel 1. Hasil Bivariat

Hubungan Anemia dengan Prestasi Belajar di SMP Negeri Kelila

\begin{tabular}{|c|c|c|c|c|c|c|c|c|}
\hline \multirow{3}{*}{ Anemia } & \multicolumn{4}{|c|}{ Prestasi Belajar } & \multirow{3}{*}{$\begin{array}{c}\text { Total } \\
\mathrm{f}\end{array}$} & \multirow{2}{*}{\multicolumn{2}{|c|}{ p-Value }} & \multirow[b]{2}{*}{ OR } \\
\hline & \multicolumn{2}{|c|}{ Baik } & \multicolumn{2}{|c|}{ Kurang } & & & & \\
\hline & $\mathrm{f}$ & $\%$ & f & $\%$ & & $\%$ & & \\
\hline Anemia & 3 & $7,5 \%$ & 9 & $75 \%$ & 12 & 23,1 & & \\
\hline Tidak Anemia & 37 & $92,5 \%$ & 3 & $25 \%$ & 40 & 76,9 & 0,000 & 37,0 \\
\hline Total & 40 & $100 \%$ & 12 & $100 \%$ & 52 & 100 & & \\
\hline
\end{tabular}


Berdasarkan tabel 1 Siswi yang tidak mengalami anemia sebanyak 37 orang $(92,5 \%)$ berprestasi baik, dan yang tidak anemia sebanyak 3 orang $(25 \%)$ berprestasi kurang. Sedangkan siswi yang anemia dengan prestasi baik sebannyak 3 orang (7,5\%), dan siswi yang anemia dengan prestasi kurang sebanyak 9 orang $(75 \%)$.

Analisa statistik uji Chi-Square $(P$ Value $\leq 0,05)$ dengan hasil nilai signifikan $(p)$ 0,000. Sehingga dapat diambil kesimpulan, bahwa terdapat hubungan antara anemia dengan prestasi belajar pada siswi di SMP Negeri Kelila dengan nilai OR 37,000 yang berarti siswi yang tidak mengalami anemia berpeluang 37 kali lebih besar mengalami prestasi dalam belajar yang baik dibandingkan siswi yang mengalami anemia.

\section{PEMBAHASAN}

\section{Analisis Bivariat}

\section{Hubungan antara Anemia dengan Prestasi Belajar}

Berdasarkan data hasil penelitian yang diperoleh dari 52 siswi, yang tidak mengalami anemia sebanyak 37 orang $(92,5 \%)$ berprestasi baik, dan yang tidak anemia sebanyak 3 orang (25\%) berprestasi kurang. Sedangkan siswi yang anemia dengan prestasi baik sebanyak 3 orang $(7,5 \%)$, dan siswi yang anemia dengan prestasi kurang sebanyak 9 orang $(75 \%)$.

Analisa statistik uji Chi-Square ( $P$ Value $\leq 0,05)$ dengan hasil nilai signifikan $(p)$ 0,000. Sehingga dapat diambil kesimpulan, bahwa terdapat hubungan antara anemia dengan prestasi belajar pada siswi di SMP Negeri Kelila Kabupaten Mamberamo Tengah.

Penelitian yang sama juga telah dilakukan Wulan (2015) di SMPN 2 Semarang bahwa sebagian besar siswi tidak mengalami anemia, dan adanya hubungan kadar hemoglobin dengan prestasi belajar yang didapatkan nilai $\mathrm{p}=0,042$. Penelitian yang juga dilakukan oleh Rieska (2012) pada siswi SMPN 2 Bringin Ngawi Jawa Timur bahwa adanya hubungan kadar hemoglobin dengan prestasi belajar.

Berdasarkan penelitian Indah (2013) terdapat 29 responden yang anemia terdapat 12 respoden $(17,1 \%)$ mempunyai prestasi belajar yang baik, sementara 17 responden $(24,3 \%)$ dengan prestasi belajar kurang baik. Terdapat 41 responden $(58.6 \%)$ yang tidak anemia, 30 responden $(42,9 \%)$ mempunyai prestasi belajar yang baik sedangkan 11 responden $(15,7 \%)$ dengan prestasi kurang baik. Berdasarkan hasil analisis Chi Square diperoleh nilai $x 2=7.153$ dengan $p=0,007$. Dengan hasil tersebut disimpulkan adanya hubungan antara kadar hemoglobin dengan prestasi belajar siswa SD Negeri 1 Bentangan Wonosari Kabupaten Klaten.

Dikatakan bahwa pada kondisi anemia daya konsentrasi dalam belajar tampak menurun (Sediaoetama, 2014). Anemia karena defisiensi zat besi pada anak-anak akan mengganggu kemampuan belajar mereka di sekolah. Bukti yang tersedia menunjukkan gangguan pada perkembangan psikomotor dan kemampuan intelektual serta perubahan perilaku setelah terjadi anemia defisiensi zat besi (Gibney dkk, 2013). Kekurangan zat besi pada anak juga dapat menyebabkan penurunan nilai tes psikologi, tes konsentrasi, mengurangi kemampuan belajar konsep dan menurunkan daya ingat. Pada anak-anak kekurangan besi menimbulkan apatis, mudah tersinggung, menurunnya kemampuan untuk berkonsentrasi dan belajar (Almatsier, 2013).

Dukungan lingkungan untuk konsumsi Tablet Tambah Darah juga didapat dari pemerintah. Kemenkes RI, Mengeluarkan kebijakan dalam program Pembangunan Indonesia 
Sehat dan Rencana Pembangunan Jangka Menengah Nasional (RPJMN) 2015-2019 yakni guna pembinaan dan perbaikan gizi masyarakat salah satunya adalah pemberian Tablet Tambah Darah (TTD) bagi remaja putri dengan target sebesar 30\% pada tahun 2019.

\section{KESIMPULAN}

Berdasarkan penelitian mengenai hubungan anemia dengan prestasi belajar. Hasil simpulan yang didapat pada penelitian ini adalah:

1. Berdasarkan hasil analisis univariat, dari 52 siswi di SMP Negeri Kelila Kabupaten Mamberamo Tengah yang diteliti didapatkan hasil siswi yang tidak mengalami anemia sebanyak $(76,9 \%)$ dan yang mengalami anemia sebanyak $(23,1 \%)$.

2. Terdapat hubungan antara anemia dengan prestasi belajar pada siswi SMP Negeri Kelila Kabupaten Mamberamo Tengah Tahun $2018(P$-Value $<\alpha(\mathrm{p}=0,00)$.

\section{SARAN}

\section{Bagi Sekolah}

Diharapkan kepada pihak sekolah agar bekerja sama antara pihak sekolah, masyarakat, dinas kesehatan dan puskesmas untuk mengadakan seminar mengenai anemia. Serta dapat melakukan pemeriksaan berkala. Dan jika siswa yang mempunyai kadar hemoglobin rendah agar bisa ditangani.

\section{Bagi Orang Tua}

Diharapkan agar mengingatkan kepada anaknya menjaga pola makan dan mengkonsumsi makanan yang banyak mengandung zat besi agar kebutuhan besi terpenuhi sehingga dapat meminimalkan kejadian anemia.

\section{Bagi Institusi Pendidikan}

Dapat memberikan masukan positif dalam upaya meningkatkan pengetahuan mahasiswa mengenai hubungan anemia dengan prestasi belajar.

\section{Bagi Pemerintah}

Bagi pemerintah diharapkan dapat melakukan sosialisasi ke sekolah-sekolah terutama daerah pedalaman agar program pemberian Tablet Tambah Darah (TTD) ini dapat tercapai dengan baik dan dapat menurunkan angka anemia pada remaja.

\section{DAFTAR PUSTAKA}

Almatsier, S. 2013. Prinsip Dasar Ilmu Gizi. PT Gramedia Pustaka Utama. Jakarta.

American Academy of Child Adolescent Psychiatry. 2013. ADHD Parents Medication Guide. Elaine Schlosser Lewis Fund. Washington DC.

Arikunto, S. 2013. Prosedur Penelitian Suatu Pendekatan Praktik. Rineka Cipta. Jakarta.

Arini, NKS. 2012. Pengaruh Tingkat Intelegensi dan Motivasi Belajar Terhadap Prestasi Akademik Siswa Kelas II SMA Negeri 99 Jakarta Tahun 2012. Jurnal Psikologi, [ejournal]. Available

at: http://publication.gunadarma.ac.id/bitstream/123456789/1938/1/Artikel_10504121.pd f.

Aryani, R. 2014. Kesehatan Remaja Problem dan Solusinya. Salemba Medika. Jakarta.

Astiandani. 2015. Hubungan Kejadian Anemia dengan Prestasi Belajar Matematika pada Remaja Putri Kelas 11 di SMAN 1 Sedayu Tahun 2015. Skripsi. Sekolah Tinggi Ilmu Kesehatan Aisyiyah Yogyakarta.

Ahmadi, Abu. 2016. Psikologi Sosial. Rineka Cipta. Jakarta. 
Dinas Kesehatan Provinsi Papua. 2015. Profil Kesehatan Provinsi Papua Tahun 2015. Jayapura.

Gibney, Michael J., Margetts, Barrie M., Kearney, John M., Arab Lenore. 2013. Gizi Kesehatan Masyarakat. EGC. Jakarta. Hardinsyah. 2017. Ilmu Gizi Teori Dan Aplikasi Edisi 1. EGC. Jakarta.

Hasanah. U. Hubungan Anemia Defesiensi Zat Gizi Besi dengan Hasil Belajar Biokimia Mahasiswa Biologi FMIPA Unimed Tahun 2015. Jurnal Keluarga Sehat Sejahtera 2015. Universitas Negeri Medan.

Indriawati Herman, Indah. 2010. Hubungan Anemia dengan Kebiasaan Makan, Pola Haid, Pengetahuan Tentang Anemia dan Status Gizi Remaja Putri di SMUN 1 Cibinong Kabupaten Bogor Tahun 2010. Skripsi. Universitas Indonesia.

Indah, K. 2013. Hubungan Antara Kadar Hemoglobin Dengan Prestasi Belajar Siswa SD Negeri 1 Bentangan Wonosari Kabupaten Klaten Tahun 2013. Skripsi. Sekolah Tinggi Ilmu Kesehatan Aisyiyah Yogyakarta.

Kemenkes R.I. 2018. Riset Kesehatan Dasar; RISKESDAS. Balitbang Kemenkes RI. Jakarta. Mansjoer, Arief. 2010. Kapita Selekta Kedokteran edisi 4. Media Aesculapius. Jakarta.

Proverawati. 2013. Buku Ajar Gizi Untuk Kebidanan. Nuha Medika. Jakarta.

Reksodiputro. 2016. Kanker Bukan Titik Akhir. Rayyana Komunikasiindo. Jakarta.

Respati. 2012. Buku Pintar Asuhan Keperawatan. Cakrawala Ilmu. Yogyakarta.

Sediaoetama, A. 2010. Ilmu Gizi. EGC. Jakarta. Slameto. 2015. Belajar dan Faktor-Faktor Yang Mempengaruhi. Rineka Cipta. Jakarta 